\title{
DO AMOR QUE SANGRA, EJACULA
}

Gabrielle da Silva Forster (FURG) ${ }^{1}$

Resumo: Sendo a homotextualidade um aspecto recorrente nas obras de Caio Fernando Abreu e de Reinaldo Arenas, pretende-se observar como ela é abordada em alguns de seus escritos, objetivando descobrir se, e em que sentido, a referida temática é capaz de rachar a lógica sob a qual se classifica e se aprisiona o desejo.

Palavras-chave: Homotextualidade, Erotismo, Desejo.

Resumen: Por ser la homotextualidad un aspecto recurrente en las obras de Caio Fernando Abreu y de Reinaldo Arenas, se propone observar como ella es abordada en algunos de sus escritos, visando descubrir si, y en qué sentido, la referida temática es capaz de romper con la lógica bajo la cual se clasifica y se encarcela el deseo.

Palabras-clave: Homotextualidad, Erotismo, Deseo.

A atmosfera de mal-estar e desassossego que fervilha no universo ficcional caiofernandiano e areniano se relaciona intimamente com a posição periférica ocupada por seus personagens, pois é do debater-se constante com entraves à livre circulação do desejo que emergem sujeitos fictícios sempre esquivos à colonização de sua identidade. Marginais, subalternos, estranhos estrangeiros, ex-cêntricos, expatriados. Adjetivos vários podem ser utilizados para definir esses corpos marcados pelo estigma da diferença no cerne da intolerância. Não há como negar o desajuste inquieto dos personagens de Arenas, cativos de uma ótica cubana

1 O presente texto é fruto de pesquisas referentes à tese que venho desenvolvendo. 
patriarcal, acentuada pela sequência de duas ditaduras totalitárias e pelas situações de miséria e analfabetismo na qual estava imersa a maior parte da população. Nem o desacorde dos personagens de Abreu, ensaiando relações e contatos outros, seja em desarmônicas metrópoles, ou no insistente toque de recolher dos anos de chumbo, castradores de toda a liberdade de expressão. Portanto, configura-se nessas obras um movimento expansivo com relação à experiência, um abalo de categorias dogmatizadas, ao problematizar a rigidez das representações identitárias na tensão entre as regras e a desobediência, estimulando na tessitura do texto a força do desejar.

Na exploração exaltada do desejo, considerado aqui, com Suely Rolnik e Felix Guattari, como "todas as formas de vontade de viver, de vontade de criar, de vontade de amar, de vontade de inventar uma outra sociedade, outra percepção de mundo, outros sistemas de valores" (GUATTARI; ROLNIK, 2000, p. 215), o viés homoerótico é uma entrada consciente e necessária para a análise das obras de Caio Fernando Abreu e de Reinaldo Arenas. Através da figuração de personagens gays e seus ávidos olhares aos corpos proibidos; nas variações do desejo longe dos moldes da heteronormatividade compulsória e também na apropriação 
desestabilizadora das palavras de ordem e dos mecanismos de exclusão que configuram a condição de subalternidade sexual. Tais obras racham a lógica sob a qual se classifica e se aprisiona o desejo, implodindo, assim, os limites criados para o gosto e o prazer. Por isso, aos termos utilizados para caracterizar inicialmente a posição de alteridade dos personagens arenianos e caiofernandianos, devemos, com certeza, acrescentar o vocábulo queer, considerado em sua ressignificação positiva da taxonomia pejorativa que une estranheza e homossexualidade, pois a reavaliação de termos como esse "sugiere que el habla puede ser 'devuelto' al hablante de una forma diferente, que puede citarse contra sus propósitos originales y producir una inversión de sus efectos" (BUTLER, 1997, p. 35). Nesse sentido, a repetição recontextualizada de dita palavra ofensiva indica o mesmo caráter resistente que observamos nas obras de Abreu e de Arenas, quando recuperam o preconceito homofóbico, deslegitimando-o de sua pretensa verdade, ancorada em relações excludentes de poder.

A consideração do caráter performativo do discurso permite a Judith Butler afastar a identidade sexual de uma compreensão essencialista e expô-la como constructo social, produzido através da reiteração ritualizada de 
normas reguladoras. Em sua perspectiva, próxima a Lacan, o sujeito só significa na linguagem, ou seja, somente "se llega a 'existir' en virtud de esta dependencia fundamental de la llamada del Otro" (BUTLER, 1997, p. 22) e "solo se puede decir 'yo' en la medida en que alguien se haya dirigido a mí y que esa apelación haya movilizado mi lugar en el habla" (BUTLER, 2002, p. 317). Portanto, a maneira como somos definidos, qualificados, é inseparável de uma construção histórica e cultural, imbricada, inevitavelmente, em relações de poder, como já alertava Foucault. Assim, o discurso que nos nomeia e nos forma também nos controla e nos sujeita, pois como afirma Butler:

La interpelación es un acto de habla cuyo "contenido" no es ni verdadero ni falso: su primera tarea nos es la descripción. Su objetivo es indicar y establecer a un sujeto en la sujeción, producir sus perfiles en el espacio y en el tiempo. Su operación repetitiva tiene el efecto de sedimentar esta "posición con el tiempo." (1997, p. 62)

Na produção identitária, as classificações genéricas têm um papel preponderante, visto que desde o nascimento o sujeito já é marcado e engendrado dentro dos parâmetros masculino/feminino que ao longo de sua existência deverá encarnar para não ser considerado desvio de acordo com 
a matriz heterossexual. É por isso que de acordo com a referida teórica, sexo e gênero não se opõem e não podem ser separados. Não há qualquer pureza ou essência biológica no sexo; ambos nascem juntos e só funcionam através da reiteração constante de atos performativos, que nos impulsionam a repetir um conjunto de regras dadas a priori. Por conseguinte,

el sexo no solo funciona como norma, sino que además es parte de una práctica reguladora que produce los cuerpos que gobierna, es decir, cuya fuerza reguladora se manifiesta como una especie de poder productivo, el poder de producir - demarcar, circunscribir, diferenciar - los cuerpo que controla. (BUTLER, 2002, p. 18)

No entanto, nesse jogo de citações constantes, nesse ritual reiterativo de regras excludentes e autoritárias, ancoradas em um discurso heteronormativo que se verbaliza como único e "intenta crear una realidad más que dar cuenta de una realidad que ya existe" (BUTLER, 1997, p. 62), há igualmente a possibilidade de ressignificar as alocuções que nos capturam. Se o ato performativo cria aquilo que nomeia através da repetição continua, que de tanto repetir-se oculta o seu caráter de convenção, esse mesmo ato de citação também revela sua inevitável recontextualização e, por 
conseguinte, a impossibilidade de recuperar com exatidão o lugar ao qual somos acoplados. Ao considerar, com Derrida, que "la fuerza del performativo proviene precisamente de su descontextualización, de su ruptura con un contexto previo y de su capacidad para sumir nuevos contextos" (BUTLER, 1997, p. 239), e ao compreender o gênero enquanto materialização performativa, a teórica citada abre espaço para um novo debate sobre a sexualidade e os papéis restritivos vinculados a ela. Nessa empreitada, não se trata de negar os termos e o discurso através dos quais se é sujeitado, mas de questionar a lógica heteronormativa desde sua estrutura interna, de rachá-la, utilizando-se desse discurso indevidamente, pois, como afirma:

La posibilidad política de utilizar la fuerza del acto de habla contra la fuerza de la ofensa consiste en hacer una apropiación inadecuada de la fuerza del habla que opera en contextos anteriores. Sin embargo, el lenguaje que contrarresta las ofensas debe repetir aquellas ofensas sin por lo tanto llegar a recriarlas. (BUTLER, 1997, p. 71)

No âmbito dessa nova perspectiva sobre sexualidade e gênero, denominada teoria queer, da qual Judith Butler participa como uma das precursoras, o lugar relegado à homossexualidade vem sendo repensado e reconfigurado 
a partir da desconstrução dos parâmetros sob os quais se funda a lógica heterocêntrica. E embora a discussão tenha sido iniciada no final dos anos oitenta do século passado, ela se estende até o momento presente, revelando igual urgência e necessidade de mobilizar a insurgência de um novo olhar sobre a homoafetividade. Mesmo que a inserção do "politicamente correto" no discurso contemporâneo tenha aberto espaço para que temáticas anteriormente excluídas adquirissem maior visibilidade, o preconceito homofóbico não se extinguiu e tomamos conhecimento de sua força através de notícias que abordam as diversas formas de violência, na maior parte das vezes impune, contra sujeitos homo-orientados.

Ao mesmo tempo, é possível igualmente reconhecê-lo em discursos mascarados, que tentam ocultá-lo sem conseguilo de todo. Portanto, refletir sobre a homotextualidade nos escritos de Caio Fernando Abreu e de Reinaldo Arenas não serve apenas para observar como ela se configura literariamente nestes textos, objetivando não ignorar um dos aspectos marcantes e transgressivos de suas obras, mas também, e principalmente, para permitir uma retomada da discussão sobre a homossexualidade, apontando, a partir das estratégias estéticas encontradas por estes escritores 
para desestabilizar o discurso excludente, novas formas de considerar esta questão.

$\mathrm{Na}$ fiç̧ão caiofernandiana há textos que exploram as relações homoeróticas de forma explícita, descrevendo sem pudor o contato físico entre dois homens e exaltando o desejo e o corpo. Nestes, o mais íntimo se instala: suor, cheiro, saliva, esperma, aspectos corporais quase sempre denegados, mas que revelam um alto grau de particularidade e de proximidade corpórea. A atração se revela na reverberação de todos os sentidos e o olhar se excita na observação de muitas porções do outro, em pedaços desvendados, em cantos quase sempre recobertos. Dessa forma, a carne é exposta em sua nudez, sem melindre, com tudo que a compõe, para desconstruir essa reserva em relação à matéria e perscrutar novos elementos de prazer, assumindo sem recato o corpo, seus aspectos, suas partes, sua possibilidade ampla de satisfação com outro corpo.

Em "Anotações sobre um amor urbano", a maneira como o contato é descrito alude à penetração, mas revela uma satisfação que vai muito além do ato, que é delírio, união arrebatadora, como indica o narrador: "naufrago em tua boca, esqueço, mastigo tua saliva, afundo. Escuridão e umidade, calor rijo do teu corpo contra a minha coxa, calor rijo do meu corpo contra a tua coxa" (ABREU, 2005a, p. 156). O desejo 
se revela como sede, calor, vontade desenfreada pelo corpo alheio, em sua composição vária, nos detalhes que se tornam atrativos àquele que olha. Porém, como em "Terça-feira gorda", longe dos estereótipos criados para enquadrar quem deseja alguém do mesmo gênero que o seu:

Ele encostou o tronco suado no meu. Tínhamos pelos, os dois. Os pelos molhados se misturavam. Ele estendeu a mão aberta, passou no meu rosto, falou qualquer coisa. O quê, perguntei. Você é gostoso, ele disse. E não parecia bicha nem nada: só um corpo que por acaso era de homem gostando de outro corpo, o meu, que por acaso era de homem também. (ABREU, 1987, p. 48)

Não há receio em falar de sexo e em explorar caminhos para a sexualidade na literatura do referido escritor gaúcho. Assuntos reservados, como a masturbação, podem se inserir na narrativa com naturalidade, conforme é possível observar em "Pequeno monstro", conto no qual o toque prazeroso entre dois primos é descrito em pormenores, construído como um lento desabrochar, inclusive permeado de certa ingenuidade e trivialidade, tanto que os dois riem depois de se masturbarem e seguem a amizade sem constrangimento algum. A menção detalhada do encontro e a alusão explícita ao sexo e à nudez figura ao lado de uma construção que revela inocência, descoberta, surpresa. A dificuldade do 
narrador em explicar exatamente o que acontece com seu corpo, ao lado de um vocabulário que une festas e objetos desejados na infância, contribui para isso:

Ele chegou mais perto. Então pegou outra vez no meu braço, cuspiu na palma da minha mão e levou até o pau dele. Ele cuspiu na palma da mão dele e levou até o meu pau. Quente molhado rijo macio. A cama rangia. Eu cheguei ainda mais perto. Aquela coisa crescia dentro de mim feito louca de atar, como se o meu corpo fosse arrebentar e de dentro dele saíssem balões, bandeirinhas coloridas de Santo Antônio, penduricalhos dourados de Árvore de Natal, confete e serpentina de Carnal, sei lá que mais. Mais depressa ele disse. Mais depressa, vem junto. (ABREU, 2005b, p. 126)

Com a citação acima notamos ênfase nos genitais, mas é preciso ressaltar que a leitura completa do conto nos permite inseri-lo na linha de abordagem das relações homoeróticas que a obra caiofernandiana assume, pois a satisfação ultrapassa essa forma de contato, ampliando-se na exploração de outros sentidos, de sensações provocadas pelo choque entre outras partes do corpo e pelo afeto, pelo carinho, conforme podemos observar nas seguintes passagens, descritas logo após o frenesi dos dois: "ele passou as mãos molhadas nas minhas costas. Eu passei as 
mãos molhadas nas costas dele. Ele afastou a boca da minha, depois deitou a cabeça no meu ombro" (ABREU, 2005b, p. 127); "ele passou a língua na curva do meu pescoço. Eu enrolei os dedos naquele triângulo de pelos crespos na cintura dele" (ABREU, 2005b, p. 127). A ternura entre os dois visualizada neste conto se estende a muitos textos do escritor gaúcho, pois em sua ficção geralmente as relações homoeróticas apontam para um encontro que vai além do ato carnal, ou seja, indicam que o anseio pelo outro não se restringe ao contato corporal, mas reclama a criação de um vínculo mais profundo de afeto.

Logo, tanto a inserção de temas tabus quanto a consideração da dimensão corporal em sua totalidade e a figuração em sua obra de relações homoafetivas e não simplesmente homoeróticas, alargam a perspectiva que geralmente envolve a (homo)sexualidade. Esta abertura se estende por muitos textos de Abreu, entre os quais se pode citar a novela Pela noite, na qual há menção a resquícios de dejeto na relação anal, para problematizar os sentimentos de culpa e vergonha do narrador, indicando na reflexão do outro personagem que o contato sexual e o desejo entre dois homens não se resume a essa prática, mas implica outras formas de prazer, cumplicidade e amizade, experimentados 
por este em seu relacionamento passado. Nesse sentido, a obra caiofernandiana se coloca em consonância com os estudos queer, posto que esses:

contemplan necesariamente una reconsideración del cuerpo humano, urgida tanto por la necesidad de combatir la primacía obsesiva de la heterosexualidad en lo genital como única sede de placer legítimo y como metonimia rectora para establecer la identidad del individuo, como por la propuesta creciente de propiciar la erotización total del cuerpo. (FORSTER, 1998, p. 50)

A presença do homoerotismo e a ampliação da ótica geralmente limitadora com a qual se aborda dita questão que notamos na literatura de Abreu é igualmente marca constante na obra de Arenas, atravessando toda a sua produção ficcional. Em seus romances, contos e poemas, verifica-se a exploração do desejo homossexual unida ao preconceito que o envolve ao mesmo tempo em que contribui para acentuar o universo repressivo configurado em sua obra funciona como elemento violador da ordem heterossexual imposta. Reivindicado e inserido em uma linguagem transgressora que desestabiliza as formas tradicionais da literatura, o homoerotismo da obra areniana é inseparável da contestação geral de sua ficção 
frente à opressão de qualquer espécie. Portanto, faz parte da reivindicação pela liberdade de expressão afirmada continuamente tanto nos aspectos formais de sua escritura quanto na conduta reacionária de seus personagens, sendo por isso que Gutiérrez afirma que "sexo, escritura y política conforman tres de los vectores básicos sobre los que se cimienta la trajectoria literaria del escritor" (2007, p. 50).

Assim como ocorre na obra de Abreu, na literatura de Arenas também não há pudor em abordar o sexo, as sexualidades e o prazer. Em muitos de seus livros a masturbação, temática com frequência silenciada e considerada imprópria, é praticada abertamente pelos seus personagens, em meio aos mais variados e às vezes excêntricos desejos, como os de Fortunato, que nesta prática chega a pensar na própria mãe ou num ato de violência contra a prima. Há aqui uma forma de libertação total do desejo que, na obra areniana, encontra sua maior expressão em El color del verano, romance que poderia ser resumido como uma grande festa erótica, na qual não há limites para o prazer e no qual se reconhece a carnavalização do gozo. Com isso, nota-se que soltar as rédeas do desejo é uma forma de, em meio à atmosfera extremamente repressiva encontrada na obra do escritor cubano, transgredir de forma abrupta com toda e qualquer ordem, tornar-se soberano. 
Mas nem sempre é pela via do escândalo, da ruptura absoluta com as normas, que o sexo como elemento transgressor figura na literatura de Arenas. Nesta, na maior parte das vezes, o desejo pelo outro não se restringe ao ato sexual. O almejado por muitos de seus personagens vai além do prazer carnal, pois estes revelam a carência de um amigo, de um companheiro, de alguém com quem compartilhar dores e alegria, como podemos observar em El palacio de las blanquísimas mofetas, no momento em que Fortunato revela que em sua imaginação às vezes "era un primo su héroe, su amante secreto, su amigo. Era un niño en el cual toda la pureza del mundo (toda belleza), todo lo que él hubiese querido ser (hubiese podido ser, quizá), hallaba oportunidad de manifestarse" (ARENAS, 1983, p. 104).

Igual ao que encontramos na literatura de Caio Fernando Abreu, aqui também a textualização do desejo homoafetivo não se limita aos prazeres do corpo, mas indica a busca de um contato mais intenso com o outro, embalado pelo tom do que se chama amor e compreensão. Por isso, quando Héctor, narrador da segunda parte de Otra vez el mar, se sente atraído pelo adolescente que aproveita suas férias na cabana ao lado da sua, não é apenas ao corpo deste que se volta seu desejo, mas à sua vitalidade, à sua maneira de 
estar no mundo, como podemos observar nesta passagem, na qual o olhar e a admiração deste pelo outro reside no movimento, no desabrochar de vida que representa:

$$
\text { Ae, ae }
$$

$$
\text { O }
$$

D

es él, que outra vez silba en el portal

N

\section{A}

0

$\mathrm{R}$

B

(ARENAS, 2002, p. 210)

Além disso, o corpo na ficção de Arenas também é considerado em sua totalidade, em consonância com essa forma de desejo que não reside apenas no sexo. Se em El color del verano a penetração é reivindicada constantemente e o membro masculino exacerbado a tal ponto que o erótico se torna paródico, em suas outras obras geralmente o que atrai o personagem são outros aspectos: a força, ou até 
mesmo a fraqueza, a maneira de vestir-se, de comportarse, a agilidade, o humor, como podemos observar nesta passagem de El palacio de las blanquísimas mofetas, na qual Fortunato tenta se masturbar pensando em mulheres, mas só consegue ao lembrar-se do amigo:

Sólo cuando apareció Avi, alto, flaco, en sus pantalones estrechos, usurpando la cara de los otros, riendo y haciendo equilibrios sobre extrañas vegetaciones, se estimulo el ritmo de sus frotaciones, $y$ en medio de un torbellino de rostros fragmentados, desesperados, y extrañas hojas que se desplazaban, Fortunato logró finalmente el tranquilizador objetivo. (ARENAS, 1983, p. 215)

Sendo assim, tanto na obra de Caio Fernando Abreu quanto na de Reinaldo Arenas, a exploração de outras partes do corpo como atrativos para o desejo e a indicação de que a relação homossexual inclui outras formas de ligação não limitadas ao sexo são fatores que permitem ampliar a ótica sob a qual o discurso heteronormativo compulsório se constrói, visto que este focaliza apenas o lado carnal destes contatos, ignorando o sentimento que pode haver por trás da união entre pessoas do mesmo sexo.

Porém, essa não é a única maneira de desestabilizar o prisma homofóbico. Na ficção de ambos os escritores em 
alguns textos o padrão masculino e heterossexual é rachado, desarticulado, o que igualmente contribui para isso. É comum em muitas obras de Reinaldo Arenas que os policiais, grandes representantes do arquétipo másculo, mantenham relações sexuais com homens e ainda assim não sejam classificados no texto como homossexuais pelo fato de executarem o papel de ativos, o que é possível observar, por exemplo, em Arturo, a estrela mais brilhante, novela na qual os presos dos campos de concentração são obrigados a relacionaremse sexualmente com os guardas que cuidam do local. Nesse sentido, por trás deste fato é possível reconhecer a crítica a um discurso limitado e distorcido que, identificando os sujeitos com determinados papéis, cria estereótipos dos quais alguns, que executam o mesmo ato, acabam sendo excluídos e, por conseguinte, protegidos. Ao mostrar o quão infundado pode ser essa concepção da homossexualidade, visto que separa e classifica de maneira diferente a mesma forma de desejo, e ao mostrar que este pode nascer onde menos se espera, a obra areniana abre brechas para que se repensem a sexualidade e as abordagens fechadas das quais elas não param de vazar, produzindo novos contornos.

Na literatura de Caio Fernando Abreu essa mobilidade sexual também se processa, rompendo com a unicidade 
e com a certeza com a qual o paradigma heterocêntrico envolve e divide os sujeitos de acordo com sua orientação sexual. No conto Sargento Garcia, após ser dispensado do serviço militar, o adolescente Hermes, protagonista do conto, é assediado pelo sargento encarregado de entrevistar os rapazes e com ele tem sua primeira relação sexual. Neste conto, a descrição máscula e estereotipada do militar funciona como um alerta ao fato de que o discurso que assimila a atração gay com sujeitos afeminados está fundado em uma perspectiva restrita que não considera a complexidade e a fluidez identitária. Ao recorrer ao rótulo para logo desconstruí-lo, o referido texto caiofernandiano abala a coerência sob a qual se funda o modelo heterossexual, revelando a performatividade do gênero, o seu caráter de convenção. Essa deslegitimação do discurso machista e autoritário também se processa no conto "O ovo", no qual o narrador, ao reconhecer a predisposição homo-orientada de um milico que visita sua casa, começa a provocá-lo, andando com pouca roupa pela casa e aproximando-se tendenciosamente dele, com o objetivo de vingar-se através deste do militar que Ihe tirou a noiva. No referido conto, além do abalo produzido no arquétipo masculino assimilado a esta categoria profissional, há igualmente um alarme em relação às repercussões mais nocivas do preconceito, pois 
após o assédio do narrador, o jovem militar se suicida, e, embora o motivo do ato não seja mencionado na obra, temse a impressão de que o desejo "proibido" foi o causador de tal agressão contra si mesmo.

Como demonstra Judith Butler, a retomada das palavras de ordem que capturam os sujeitos não ocorre sem ressignificação, pois "ese lenguaje no sólo viene definido por su contexto social, también está marcado por su capacidad para romper con ese contexto" (BUTLER, 1997, p. 71). Portanto, quando as literaturas areniana e caiofernandiana textualizam o discurso homofóbico ou recuperam as palavras ofensivas, ao mesmo tempo em que dão visibilidade ao preconceito e às suas repercussões nocivas, também instauram novas demarcações para estes termos e, nesse sentido, "la palabra que hiere se convierte en un instrumento de resistencia, en un despliegue que destruye el territorio anterior de sus operaciones" (BUTLER, 1997, p. 261).

Na obra de Reinaldo Arenas, a expressão "maricón" aparece com insistência, geralmente através de vozes que acusam e insultam alguns personagens. No entanto, em alguns textos ela é reivindicada pelo próprio protagonista. Em El color del verano, a recuperação constante desta palavra de ordem funciona no âmbito do excesso e da ironia: 
em mundo cheio de "maricones" ou de "pájaros", conforme denominação da obra, o estigma que recai sob o termo se desfaz na reiteração, torna-se comum nesta "comunidade". Já em Otra vez el mar, assumindo sua orientação, Héctor recorre à palavra ofensiva, porém para mostrar a violência que reside por trás desta e para desestabilizar o seu sentido: "ah mar, sé mariquita, sé mariquita para que veas" (ARENAS, 2002, p. 171), ao mesmo tempo em que revela o abuso de poder, indica o caráter de convenção do termo, que poderia ser aplicado a outros substantivos.

Essas duas formas de recorrer às palavras de ordem que classificam os sujeitos de acordo com sua orientação sexual também ocorrem na obra caiofernandiana. Em contos como "Garopaba mon amour" e "Terça-feira gorda", por exemplo, nos quais a homofobia assume sua face mais escura, os agressores se utilizam dos termos "bicha", "bichona" e "veados" para ofender: no primeiro conto um grupo de jovens que acampa numa praia catarinense, no segundo dois homens que se conhecem e se desejam numa noite de carnaval. Mas além de tornar explícito o preconceito, alertando para o perigo que há por trás da exclusão social, na obra do escritor gaúcho as palavras ofensivas também são recuperadas com o intuito de recontextualização. 
Um bom exemplo disto é o conto "Os sobreviventes", pois neste são os próprios personagens que se definem como "veado" e "sapatão", reivindicando assim estas expressões como parte daquilo que os define, porém sem que possamos reduzi-los apenas a esta característica de sua personalidade devido à composição complexa de tais sujeitos fictícios. Tal retomada é importante porque através da repetição é possível "refutar su empleo homofóbico en el campo legal, en las actitudes públicas, en la calle, en la vida 'privada'” (BUTLER, 2002, p. 322). Além disso, como afirma Judith Butler,

la ocupación, reformulación, deformación de las palabras de uno abren un difícil campo futuro de comunidad, un campo en el que la esperanza de llegar a reconocerse plenamente en los términos por los cuales uno significa seguramente terminará en desengaño. (2002, p. 338)

É a esta abertura que nos apontam as obras de Caio Fernando Abreu e de Reinaldo Arenas quando abordam a questão homossexual. Na produção de subjetividades complexas, plurais e móveis, a orientação sexual de seus personagens aparece apenas como uma pequena porção de sua identidade, evitando assim a redução subjetiva que o discurso heteronormativo produz, visto que "llamar 
a alguien roto o marimacha, homosexual o lesbiana, o heterosexual, es metonimizarlo. Es tomar la parte por el todo" (NORIEGA, p. 2). O que encontramos nestes textos é um desejo fluido, nômade, capaz de desabrochar nos lugares mais insuspeitados; líquido o suficiente para jorrar o gozo através da incitação de uma multiplicidade de sentidos. Por isso, o homoerotismo atravessa a literatura dos referidos autores sem ser o aspecto central de suas obras. Não se trata de refletir e explorar simplesmente a situação das homossexualidades, mas de textualizar uma perspectiva mais móvel em relação ao corpo e ao desejo; de propor um novo espaço para o amor, ao mostrar um sujeito plural que transborda os rótulos.

\section{REFERÊNCIAS}

ABREU, Caio Fernando. Caio 3D: o essencial da década de 1970. Rio de Janeiro: Agir, 2005a.

. Caio 3D: o essencial da década de 1980. Rio de Janeiro: Agir, 2005b.

. Morangos mofados. São Paulo: Brasiliense, 1987.

ARENAS, Reinaldo. El palacio de las blanquísimas mofetas. Barcelona: Argos Vergara, 1983.

. Otra vez el mar. Barcelona: TusQuets, 2002.

BUTLER, Judith. Cuerpos que importan. Buenos Aires: Paidós, 2002.

. Lenguaje, poder e identidad. Madrid: Síntesis, 1997.

FORSTER, David William. Consideraciones sobre el estudio de la 
heteronormatividad en la literatura latinoamericana. Letras n.22 Literatura e Autoritarismo. UFSM, 1998.

GUATTARI, F.; ROLNIK. Sueli Micropolítica cartografias do desejo. 6ed. Petrópolis: Vozes, 2000.

GUTIÉRREZ, José Ismael. Reinaldo Arenas: entre el placer y el infierno. Canadá: Cursack Books, 2007.

NORIEGA, Guillermo Núñez. Desconstruyendo la homofobia. Una lectura política del erotismo. Disponível em: http://www.dvvimss.org.mx/ homofobia/DESCONSTRUYENDO LA HOMOFOBIA guillermo nunez. pdf Acesso em: 21 de jan de 2014

Gabrielle da Silva Forster é mestre em História da Literatura pela Universidade Federal do Rio Grande e doutoranda em Estudos Literários pela Universidade Federal de Santa Maria, tendo parte de sua pesquisa desenvolvida na Universidade de Salamanca, Espanha. 